\title{
Promoção e propaganda de medicamentos em ambientes de ensino
}

\author{
Drug promotion and advertising in teaching environments \\ Promoción y propaganda de medicamentos en ambientes de enseñanza
}

Na sociedade moderna, o medicamento vem crescentemente assumindo funções que extrapolam muito o caráter farmacoterapêutico, em virtude de crenças e valores que influenciam as formas de pensar e agir quando se está doente. Sendo prescrito, vendido e usado de forma inadequada, sobretudo quando há alternativas não farmacológicas ou quando não se agiu de forma preventiva, promovendo a saúde também pela implementação de políticas sociais que ampliem a qualidade de vida da população, os medicamentos podem ter efeitos adversos e impor gastos desnecessários aos indivíduos ou aos governos (Barros, 2004, 2002).

Ao tratar o medicamento como uma mercadoria indistinta das demais, as técnicas publicitárias vêm se sofisticando e utilizando instrumentos que reforçam o processo de medicalização. (Barros, 2008a, 2008b). Nesse contexto, vêm se multiplicando as denúncias de pressão dos fabricantes não só sobre os profissionais que prescrevem medicamentos ou estão em fase de formação para fazê-lo, mas também sobre legisladores, pesquisadores e autoridades reguladoras. Entre essas denúncias, destaquem-se o texto de Marcia Angell (2004), ex-editora-chefe do New England Journal of Medicine, e a louvável iniciativa do Comitê Internacional de Editores de Revistas Médicas, que estabelece princípios éticos - discutidos e aperfeiçoados desde o final dos anos 1970 - para normas de publicação; em 2001 (http://www.icmje.org/sponsor.htm) 13 editores de revistas de renome internacional firmaram um documento em que se manifestava a preocupação com a qualidade dos ensaios clínicos publicados e com a ingerência dos fabricantes na liberdade dos pesquisadores (International Committee of Medical Journal Editors, 2008).

A Association of American Medical Colleges (AMC), entidade que congrega faculdades de medicina nos EUA, elaborou um relatório em que chama a atenção para os riscos e conflitos de interesses entre a indústria e a academia, sugerindo formalmente a proibição de brindes, a centralização do manejo de amostras grátis (se permitidas), a restrição das visitas de propagandistas a médicos a horários fora do turno assistencial e eventuais sessões de divulgação científica com a presença desses agentes, mas com a possibilidade de debate com pessoal qualificado da instituição acadêmica (Report of the AAMC Task Force on Industry Funding of Medical Education, 2008). Essas oportunas recomendações ultrapassam o sugerido

${ }^{1}$ Graduado em Medicina. Departamento de Saúde Coletiva, Faculdade de Medicina, Universidade Federal de Juiz de Fora. Campus Universitário, Juiz de Fora, MG. 36.036-900 josebarros@uol.com.br 
em moção aprovada no Congresso de Educação Médica da ABEM de 2006, referida pelo texto de Palácios, Rego e Lino, que abre este debate e que ora comentamos. Centradas no papel do propagandista, as sugestões desse Congresso são absolutamente relevantes, e esperamos que sejam integralmente adotadas nos centros de formação médica (faculdades e hospitais de ensino) do país.

O texto em questão desenvolve o tema proposto com argúcia e respaldo em referencial bibliográfico pertinente, representando uma importante contribuição ao debate em curso no Brasil. Neste momento, espera-se que, por intermédio de audiência pública, a Agência Nacional de Vigilância Sanitária (Anvisa) desencadeie o desfecho desse debate, que vem se arrastando nos últimos dois anos, sobre a revisão da RDC $102^{2}$

Quando da Consulta Pública n 84, lançada em novembro de 2005, um número significativo de entidades públicas e privadas apresentaram uma série de sugestões para o aperfeiçoamento da legislação em vigor, fruto de fórum realizado em novembro de 2005 na Escola Nacional de Saúde Pública da Fundação Oswaldo Cruz. Entre as 19 as propostas apresentadas no Fórum, as mais significativas se referiam ao controle mais estrito de brindes e amostras-grátis de medicamentos e à proibição total da propaganda dirigida ao público consumidor. Essa proibição também foi objeto de recomendação do Conselho Nacional de Saúde, em reunião de março de 2007, a partir de moção apresentada pelo Instituto Brasileiro de Defesa do Consumidor (Idec) e pela Sociedade Brasileira de Vigilância de Medicamentos (Sobravime), assim como de Proposta aprovada na $1^{\text {a }}$ Conferência Nacional de Vigilância Sanitária, realizada em Brasília, de 26 a 30 de novembro de 2001.

Aos argumentos do setor produtivo que evocam o preceito constitucional da liberdade de opinião, deve-se contrapor que cabe ao Estado garantir políticas públicas que visem à "redução do risco de doenças e de outros agravos" (Art. 196 da Constituição) e ainda que a mesma Constituição preconiza a necessidade de se assegurar o direito à vida e à integridade física e psíquica dos cidadãos. Além do mais, os códigos de auto-regulamentação, proclamados como suficientes para o controle de eventuais desvios da propaganda, têm se revelado totalmente ineficazes, como ressaltam Palácios, Rego e Lino em seu texto, cujos comentários podem ser reforçados a partir de revisão exaustiva da normativa institucionalizada pela associação internacional dos fabricantes (International Federation of Pharmaceutical Manufacturers Associations, Health Action International, 1994).

Finalmente, cabe ressaltar que ratificamos as conclusões de Palácios, Rego e Lino (2008) e a proposta de se proibir a aplicação - de influência comprovadamente negativa sobre os futuros prescritores - das diferentes artimanhas de que lança mão o setor farmacêutico, em especial através dos propagandistas e do material por eles veiculado (amostras grátis, brindes, folhetos etc.)

Exercida sobre bases racionais, a farmacoterapia implica, de fato, uma série de medidas, por um lado, restritivas à livre atuação dos produtores, na forma como ela vem ocorrendo e, por outro, estratégias didático-pedagógicas da parte do aparelho formador, sendo igualmente indispensável a criação de alternativas de atualização e educação continuada infensas ao viés mercadológico das fontes - no momento, predominantes - nessas atividades, qual seja, os departamentos de marketing da indústria farmacêutica.

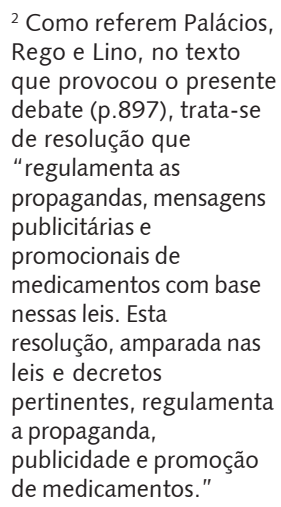


BARROS, J.A.C.

\section{Referências}

ANGELL, M. La verdad acerca de la industria farmacéutica: como nos engaña y qué hacer al respecto. Bogotá: Grupo Editorial Norma, 2006.

BARROS, J.A.C. Nuevas tendencias de la medicalización. Ciênc. Saúde Colet., v.13, supl., p.579-87, 2008a.

Os fármacos na atualidade: antigos e novos desafios. Brasília: Anvisa,

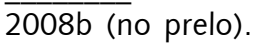

Políticas farmacêuticas: a serviço dos interesses da saúde? Brasília: Unesco/ Anvisa, 2004. (disponível também em espanhol).

J.A.C. Pensando o processo saúde e doença: a quem serve o modelo biomédico? Saúde Soc., v.11, n.1, p.7-84, 2002.

HEALTH ACTION INTERNATIONAL. Self-regulation or self-deception? Commentary on the 1994 revision of the IFPMA Code of Pharmaceutical Marketing Practices.

Amsterdam: HAI Europe, 1994.

INTERNATIONAL COMMITTEE OF MEDICAL JOURNAL EDITORS. Uniform requirements for manuscripts submitted to biomedical journals: writing and editing for biomedical publication, atualizado em outubro/2007. Disponível em: $<$ www.icmje.org/>. Acesso em: 2 jun. 2008.

PALÁCIOS, M.; REGO, S.; LINO, M.H. Promoção e propaganda de medicamentos em ambientes de ensino: elementos para o debate. Interface - Comunic., Saúde, Educ., v.12, n.27, p.895-908, 2008.

Report of the AAMC. Task force on industry funding of medical education to the AAMC Executive Council, 2008. Disponível em: <www.aamc.org/>. Acesso em: 4 jun. 2008 